\title{
Beta-Catenin-Activated Hepatocellular Adenoma
}

National Cancer Institute

\section{Source}

National Cancer Institute. Beta-Catenin-Activated Hepatocellular Adenoma. NCI

Thesaurus. Code C96759.

A hepatocellular adenoma caused by activating mutations of beta-catenin. It is characterized by the presence of nuclear atypia and absence of inflammation or steatosis. There is an increased risk of malignant transformation. 